\title{
An Interim Analysis of an Advance Care Planning Intervention in the Nursing Home
}

\section{Setting}

Susan E. Hickman, PhD ${ }^{1,2}$; Kathleen T. Unroe, MD, MHA ${ }^{2,3,5}$; Mary T. Ersek, PhD, RN, FAAN4;

Bryce Buente, $\mathrm{MPH}^{5}$; Arif Nazir, MD³; Greg A. Sachs, MD, FACD²,3,5

\begin{abstract}
Affiliations:
${ }^{1}$ School of Nursing, Indiana University, Indianapolis, Indiana

${ }^{2}$ RESPECT (Research in Palliative and End-of-Life Communication and Training) Signature

Center, Indiana University Purdue University Indianapolis, Indianapolis, Indiana

${ }^{3}$ School of Medicine, Indiana University, Indianapolis, Indiana

${ }^{4}$ School of Nursing, University of Pennsylvania, Philadelphia, Pennsylvania

${ }^{5}$ Regenstrief Institute, Indianapolis, Indiana
\end{abstract}

Contact:

Susan E. Hickman, PhD

Professor, Indiana University School of Nursing

600 Barnhill Drive, e419

United States

T: 317-274-0032

F: 317-274-2411

Email: hickman@iu.edu

This is the author's manuscript of the article published in final edited form as:

Hickman, S. E., Unroe, K. T., Ersek, M. T., Buente, B., Nazir, A., \& Sachs, G. A. (2016). An Interim Analysis of an Advance Care Planning Intervention in the Nursing Home Setting. Journal of the American Geriatrics Society, 64(11), 2385-2392. https://doi.org/10.1111/jgs.14463 


\begin{abstract}
Background/Objectives: The nursing home is increasingly the site of care for older adults near the end of life. The objective of this study was to describe processes and preliminary outcomes from the implementation of a systematic advance care planning (ACP) intervention in the nursing home setting.
\end{abstract}

Design: Specially trained project nurses were embedded in 19 nursing homes and engaged in ACP as part of larger demonstration project to reduce potentially avoidable hospitalizations.

Participants: Residents enrolled in the demonstration project for a minimum of 30 days between August 2013 and December 2014 (n=2709) and currently enrolled residents in March 2015 $(n=1591)$.

Measurements: ACP conversations were conducted with residents, families, and/or the legal representatives of incapacitated residents using a structured ACP interview guide with the goal of offering ACP to all residents. Project nurses reviewed their roster of currently enrolled residents in March 2015 to capture barriers to engaging in ACP.

Results: During the initial implementation phase, $27 \%(731 / 2709)$ of residents had participated in one or more ACP conversations with a project nurse, resulting in a change in documented treatment preferences for $69 \%$ (504/731). The most common change $(87 \%)$ was the generation of a POST (Physician Orders for Scope of Treatment) Form. The most frequently reported barrier to ACP was a lack of time.

Conclusion: The time and resource intensive nature of robust ACP must be anticipated when systematically implementing ACP in the nursing home setting. The fact that these conversations resulted in changes over $2 / 3$ of the time reinforces the importance of deliberate, systematic ACP to ensure that current treatment preferences are known and documented so that these preferences can be honored. 
Nursing homes are providing care to a growing number of older adults at the end of life. ${ }^{1-}$ ${ }^{4}$ This heightens the need for palliative care to address the complex needs of patients in this setting, including proactive identification of values, goals, and preferences through advance care planning (ACP). ${ }^{5} \mathrm{ACP}$ should ideally include a discussion about preferences for hospitalization given a growing body of evidence suggesting that hospitalizations are burdensome for older adults and can result in serious medical complications. ${ }^{6}$ Resident and family preferences are a significant factor in decisions to hospitalize, heightening the importance of ACP. ${ }^{6,7}$ The hospital is also an increasing site of death for nursing home residents, ${ }^{8}$ which may not be in keeping with their preferences. ${ }^{9}$

It is critical to communicate and document the outcomes of ACP to ensure patient preferences are honored. ${ }^{10} \mathrm{ACP}$ documentation tools include advance directives (e.g., living wills) medical orders (e.g., Do Not Resuscitate or DNR), and the Physician Orders for Life Sustaining Treatment (POLST). Although living wills are largely ineffective at altering hospitalization rates near the end of life, ${ }^{11}$ POLST comfort care orders are associated with lower rates of hospitalization among seriously ill patients. ${ }^{12-16}$

In 2012, the Centers for Medicare and Medicaid Services (CMS) identified avoidable, unnecessary, and unwanted hospitalizations of nursing home residents as a major concern that negatively impacts both quality and costs. ${ }^{17}$ To identify models of care to address these concerns, CMS funded seven, four-year long, demonstration projects, including one based at Indiana University. The multi-component Indiana Optimizing Patient Transfers, Impacting Medical Quality and Improving Symptoms: Transforming Institutional Care (OPTIMISTIC) project draws, in part, from evidence suggesting that ACP and POLST have the potential of reducing unnecessary and burdensome hospitalizations of nursing home residents. ${ }^{18-20}$ However, the literature contains few descriptions of ACP and POLST implementation. ${ }^{21}$ This paper describes the processes and preliminary outcomes of the initial implementation of systematic ACP in 19 nursing homes over a 17-month period (August 2013 - 
December 2014) including an ACP chart audit. The specific aims of this paper are to: 1) Compare nursing home residents with and without documented ACP conversations following the initial implementation of ACP; 2) Describe ACP decisions and documentation during the initial implementation phase; and 3) Identify barriers to ACP in the nursing home setting.

\section{Methods}

Overview. The OPTIMISTIC project was developed by a team of investigators at Indiana University with collaborators at the University of Indianapolis and University of Pennsylvania. This four-year initiative focusing on long stay nursing home residents began in September 2012. The multi-component intervention is delivered by 19 OPTIMISTIC nurses (RNs) with the support of 6 OPTIMISTIC nurse practitioners and a team of geriatricians. The OPTIMISTIC model contains three intervention cores designed to reduce avoidable hospitalizations: enhancing medical care through both prompt identification and management of acute conditions and improving proactive chronic care management; optimally managing transitions that do occur; and better integration of palliative care, focusing on ACP. ${ }^{19}$ The ACP intervention was implemented in August 2013 following the passage of the Indiana POST (Physician Orders for Scope of Treatment) Act in July 2013, Indiana's version of the national POLST model. ${ }^{22}$ The project goal is to provide every OPTIMISTIC enrolled resident with the opportunity to participate in ACP. The project was reviewed and declared exempt by the Indiana University Institutional Review Board.

Setting. The 19 OPTIMISTIC nursing homes are located in urban and suburban areas of central Indiana. The nursing homes represent a mix of for-profit, not-for-profit, and countyowned facilities.

Residents. Residents are Medicare fee-for-service and/or Medicaid long-stay nursing home residents; Medicare managed care residents are excluded per CMS guidelines. Long-stay was defined for the project by CMS as greater than 100 days in the nursing home or an indication on the Minimum Data Set (MDS) that there is no active or documented plan for 
discharge to the community. Per CMS requirements, residents are passively enrolled in this quality improvement project. Eligible residents or their representatives are notified about the project and provided with the option to opt-out. Less than $1 \%$ of eligible residents have opted out of the program.

OPTIMISTIC RN Training. The OPTIMISTIC nurses (RNs) have diverse background experiences, including hospice, intensive care and nursing home practice. All received extensive training including the End-of-Life Nursing Education Consortium (ELNEC)-Geriatric curriculum, a comprehensive palliative care educational program. ${ }^{23} \mathrm{RNs}$ and NPs were also are prepared as ACP facilitators through Respecting Choices Last Steps ${ }^{\circledR},{ }^{24}$ a structured process designed to elicit values, inform, and identify treatment preferences using the principles of motivational interviewing and adult learning. The program requires independent on-line training modules followed by 8.5 hours of face-to-face role play and education. The OPTIMISTIC RNs also completed additional role play activities and six were further trained as certified Last Steps Instructors. All OPTIMISTIC RNs were observed and received feedback from a certified Last Steps Instructor on their first ACP conversation with a resident or the legal representative of a resident and received on-going support regarding use of the model through the use of role play, videos, and discussion. Although the Respecting Choices Last Steps approach is focused on facilitating preparation of the POST form for physician review, confirmation, and signature, it can also serve as a guide for more general ACP conversations. Educational handouts on selected topics also were used to guide conversations and support informed decision-making.

Implementation Strategy. Prior to beginning the ACP intervention, OPTIMISTIC leadership met with corporate leaders and owners of participating nursing homes to develop an implementation plan. This plan included assistance in the development of policies related to the new Indiana POST form, a discussion around procedures for documenting ACP conversations and POST in the medical record, and hospital transfer checklists that included advance directives and POST. Information about ACP, POST and implementation strategies was 
disseminated in several forums to medical providers, directors of nursing, facility administrators, and other persons in leadership positions. OPTIMISTIC RNs provided in-service training to nursing home clinical staff on all shifts. Educational sessions were also provided to residents and families. Next, medical providers were asked to identify residents whom they believed were most in need of an ACP conversation to guide OPTIMISTIC RNs in prioritizing whom to approach initially. An informational letter for was developed to explain the still relatively new POST and the Last Steps $\mathrm{ACP}^{\circledR}$ conversation framework to the signing physician. Finally, a decision tree was developed to assist RNs in confirming that the appropriate ACP tool was being used consistent with Indiana law. (See Supplemental Figure 1 - ACP Decision Tree) The OPTIMISTIC RNs were asked to conduct 2-3 ACP conversations per week, and encouraged to take advantage of natural opportunities to engage in goals of care discussions, such as when the resident's condition changed, during care conferences, and when invited by families and residents. OPTIMISTIC RNs balanced this responsibility with other duties including education, clinical care, and quality improvement.

Data Sources. OPTIMISTIC RNs recorded information in a custom REDCap data base using task-specific encounter forms designed to capture key nursing activities. At enrollment, the RNs verified resident eligibility and recorded resident demographics and clinical information. including a review of the resident's medical record to determine whether there is an advance directive (e.g., a living will or health care power of attorney) or existing orders reflecting resident treatment preferences (e.g., Indiana Out-of-Hospital Do Not Resuscitate order, POST). Whenever an OPTIMISTIC RN engaged in an ACP conversation, she/he documented the discussion in the project data base using an ACP encounter form and in the facility medical record. Fields contained in the encounter form include the reason for the ACP discussion, the length of the discussion, whether the discussion led to a change, and details about the nature of the change. 
Advance Care Planning Audit. In addition to summary data regarding the initial 17 months of implementation, an internal audit of ACP practices was conducted from March 23 to April 10, 2015 to evaluate the status of implementation and identify any barriers to engaging in ACP. OPTIMISTIC RNs were provided lists of residents who were currently enrolled as of March 23, 2015 and asked to review each resident's medical record to identify current ACP documentation (e.g., POST forms, DNR order forms). They were asked to verify existing ACP documentation to ensure the project records were up to date regarding patient resident preferences. When there was no record of an OPTIMISTIC RN ACP conversation, they were asked to provide an explanation from a list of options. This included the option to select "other" and provide further information in an open text box. These responses were then reviewed and collapsed into categories.

Analysis. Enrolled resident demographics, ACP documentation, and the audit data were analyzed using descriptive statistics. Comparisons between residents with and without ACP conversations were analyzed using t-tests and chi-square analyses.

Results

Enrolled Residents. A total of 2709 nursing home residents were enrolled in OPTIMISTIC for a minimum of 30 days between August 1, 2013 and December 31, 2014. Enrolled residents represented an average of $72 \%$ of all residents in the 19 participating nursing homes. Residents were enrolled for an average of 11 months $(S D=5.7)$ during this period, and 43.4\% experienced one or more discharges (including temporary as well as permanent transfer out of the facility or death) during the observation period. Resident characteristics are reported in Table 1.

Comparisons between residents with and without an OPTIMISTIC ACP conversation. Residents with documentation indicating an OPTIMISTIC RN had engaged in an ACP conversation with the resident or a legal representative $(27 \%$ or $731 / 2709)$ differed in several 
ways from residents who had not $(74 \%$ or $n=2068 / 2709)$. Residents with an ACP conversation were enrolled in the project longer $(12.4$ months vs. 9.9 months, $p<.001)$ and were slightly more likely to be enrolled in hospice $(12.3 \%$ vs $9.4 \%, p=.03)$ than residents with no documented ACP conversation. See Table 1 for more information.

ACP Decisions and Documentation. Table 2 reports details of the ACP conversations and resulting documentation over the first 17 months of ACP implementation. OPTIMISTIC RNs engaged in 1136 ACP conversations involving 731 unique residents. The average number of discussions per resident was 1.6 with a range of $1-7$, with conversations taking a mean of 39.6 minutes $(S D=24.3)$. The most frequently cited reason for initiating an ACP conversation with the resident or his or her surrogate decision-maker was a change in the resident's clinical condition (29.6\%). In total, 69\% (504/731) residents experienced a change in documented care preferences as a result of one or more ACP discussion. The generation of a POST form was the most common change $(87.1 \%$ or $439 / 504)$. Because the POST form was not available in Indiana prior to July of 2013 , none of the residents had a POST form at baseline. Over half (55.2\% or $241 / 439)$ of the POST forms contained orders for Comfort Care. See Table 3 for more details.

The ACP Audit and Barriers to ACP. The audit data was collected for the 1591 currently enrolled residents residing in the facilities on March 23, 2015. A total of $42 \%$ of residents had documentation about an ACP conversation in their medical record (669/1591). A majority of these conversations were facilitated by the OPTIMISTIC RN (70\% or 465/669) and an additional number were conducted by another health care provider (30\% or $204 / 669)$ as evidenced by chart documentation. The reasons the nurses had not engaged in an ACP conversation with residents who had no documented ACP on file $(n=922)$ were as follows: the nurse had "not gotten to the resident yet" (57.6\%); the resident was believed to be ineligible (e.g., lacked decisional capacity and had no legal representative: $20.9 \%$ ); difficulty scheduling (9.8\%); the 
resident and/or legal representative declined (6\%); facility gatekeeping (3.9\%); and the resident, family, and/or legal representative were not ready to talk about the topic yet $(1.7 \%)$.

\section{Discussion}

The goal of this study was to describe the implementation of an intensive ACP intervention that is part of a larger 4-year program to reduce avoidable hospitalizations of long stay residents in 19 nursing homes. We found that $27 \%$ of enrolled nursing home residents had an ACP conversation during the initial implementation phase with a project RN. When ACP conversations by other facility staff were taken into account, just under half (42\%) of all residents had documentation of an ACP conversation. Residents with an ACP conversation were more likely to be on hospice than residents without an ACP conversation, which is consistent with the strategy of prioritizing residents who had experienced a change in status including a marked decline.

There are few published descriptions of ACP implementation in the long-term care setting and therefore minimal information available about what is required to successfully integrate ACP into practice..$^{21}$ The OPTIMISTIC experience suggests that ACP implementation in this setting requires a significant investment of resources including dedicated staff, training, and support. Prior to launching our ACP initiative, considerable time was spent in planning for implementation. This included outreach with corporate leaders, facility leadership, and medical providers to identify deficits in current protocols and processes that could undermine ACP efforts. The use of an evidence-based, intensive training model was a strategic decision to enhance the confidence of primary care providers and nursing home leaders that the OPTIMISTIC RNs had the necessary skills to lead ACP conversations with residents. OPTIMISTIC RNs also provided training to facility staff regarding ACP and the POST. This experience suggests that ACP implementation requires both leadership buy-in and a knowledgeable champion to focus on processes, procedures, and skills development. Even with 
this intensive support and infusion of resources, implementation in the clinical setting was challenging.

The OPTIMISTIC RNs were only able to reach approximately one quarter of all enrolled residents after 17 months of implementation. This rater was lower than anticipated based on prior research, though the comparability of ACP facilitation models is unclear. ${ }^{25}$ An intentional choice was made by the OPTIMISTIC team to focus on a time-intensive, comprehensive approach to ACP with the Respecting Choices Last Steps model. The commitment to high quality $\mathrm{ACP}$ is reflected in the average length of conversations of about 40 minutes and the large number of residents who participated in more than one conversation. However, a consequence of this approach may be slower ACP penetration. Residents without an ACP conversation by the OPTIMISTIC RN had overall shorter stays than those who did participate in conversations. These residents may have been more recently admitted, discharged, or died before the RN could arrange a meeting. ${ }^{26}$ Additionally, RNs were encouraged to prioritize residents who had a change in status and appeared nearer to end of life. Many conversations were held with residents who subsequently transferred out or died, with new residents in need of ACP admitted to fill the beds. This may include dying residents transferred to the hospital at the end of life. ${ }^{8}$

The audit shed light on reasons the OPTIMISTIC RNs had not engaged in ACP conversations with residents. Many residents had ACP documentation generated by other professional staff and therefore did not appear to require additional ACP. The ACP encounter form is only designed to capture discussions led by OPTIMISTIC RNs, highlighting a limitation of our initial data collection approach. The result was an underestimate of ACP penetration in the facility. Although ACP is a key role for OPTIMISTIC RNs, they reported that the primary reason they had not yet engaged in ACP was that they had simply not been able to get to the resident. Similar to other nursing home staff, OPTIMISTIC RNs have many other responsibilities competing for their time. OPTIMISTIC RNs are involved in training nursing home staff in 
recognizing and assessing residents with an acute change in status, assessment of residents with polypharmacy, and conduct root cause analyses of all hospital transfers. The challenge of juggling competing demands is likely even more pronounced among nursing home staff who add $\mathrm{ACP}$ to their existing roles with minimal to no additional training, lack dedicated time, and do not receive up-front implementation support. Ensuring that multiple staff members have the skills and training to engage in ACP is important to help achieve facility-wide ACP implementation. ${ }^{25,27}$

This interim analysis of ACP implementation provided important feedback indicating that the intervention is generally well received. Key stakeholders, including nursing home staff and physicians, are not "gatekeeping," or preventing OPTIMISTIC RNs from engaging in ACP with residents. Further, when given the opportunity to participate in ACP, only a small minority of residents and families refused, in contrast to suggestions that this is a common barrier. ${ }^{21}$ Barriers found to be common in other research such as family disagreements ${ }^{28}$ were not reported by OPTIMISTIC RNs. Importantly, these conversations are having a direct impact on resident plans of care: ACP conversations resulted in a change of medical orders in for over $2 / 3$ of residents, suggesting the prior orders did not accurately reflect patient preferences. Alternatively, the high rate of change may reflect the dynamic nature of resident/surrogate goals and the need to conduct multiple goals of care conversations over time. Research in other populations suggests that the failure to accurately document the treatment preferences of older adults in the hospital setting is common. ${ }^{29}$ The failure to know and honor patient preferences represents a serious medical error ${ }^{30}$ Fixing these errors necessitates a concerted, systematic effort. $^{31,32}$

Next Steps. The findings of this interim analysis have led to modifications in the implementation process for ACP in OPTIMISTIC. In addition to engaging in ACP as opportunities arise and in response to changes in condition, RNs are now provided with a list of specific residents to approach each month. After three unsuccessful attempts to engage the 
resident or their surrogate in an ACP conversation during the month, the OPTIMISTIC RN documents these attempts and moves on to the next resident on the list. The resident and/or surrogate is encouraged to let the RN know if there is renewed interested in discussing ACP and the resident's name goes back to the bottom of the list. This change in project protocol creates a more systematic approach to identifying residents to engage in ACP. Nursing facility leadership and clinical staff are provided with on-going feedback about the status of ACP. Another change is renewed efforts to train and engage nursing home staff to augment the efforts of the OPTIMISTIC RNs. A full-time, specialized palliative care RN role has been developed for the project to support ACP implementation and symptom management. Future analyses will examine the impact of ACP conversations and orders on avoidable hospitalizations, as well as continuing to evaluate successful implementation strategies for ACP at the facility level.

Limitations. Data represent only the initial phase of implementation. Modifications to the intervention are on-going and may alter the frequency of ACP conversations within each facility as barriers are identified and addressed. Moreover, the initial design of the OPTIMISTIC demonstration project was not explicitly guided by a formal implementation science framework. ${ }^{33,34}$ While key elements such as identifying local champions, education, and feedback were part of the initial design, ${ }^{35,36}$ we were only able to incorporate formal, regular audit and feedback and formative evaluation of the program after the program began. ${ }^{35,37,38}$ Future implementation and expansion of OPTIMISTIC will explicitly incorporate these critical implementation science components.

This project employs highly skilled and well-trained RNs who are embedded within facilities but not employed by these organizations. As a result, it was possible to invest heavily in training and education in a way that may not be realistic for more poorly resourced nursing homes. It is unclear what the ideal "goal" should be for rates of ACP within this setting or what is feasible in facilities without dedicated and highly trained staff who have ACP as a core 
component of their role. Despite these limitations, our study provides important insights about the initial phases of ACP implementation in the nursing home setting. Palliative care implementation studies currently underway ${ }^{39,40}$ may provide further evidence to refine implementation efforts.

Conclusions. Findings suggest that implementing ACP in nursing homes is challenging but possible. Front end education and clear communication with stakeholders regarding ACP implementation is essential along with support to creating policies and procedures. The time and resource intensive nature of robust ACP must be anticipated when designing programs and setting goals for ACP implementation in the nursing home setting. The fact that these conversations resulted in changes over $2 / 3$ of the time reinforce that deliberate, systematic ACP is essential to ensuring that current treatment preferences are known and accurately documented. 


\section{ACKNOWLEDGMENTS}

We are grateful to the nursing home residents enrolled in OPTIMISTIC and their families for participating in this demonstration project. We thank the nursing homes and nursing home staff who collaborate with the OPTIMISTIC project. We are also deeply appreciative of our OPTIMISTIC nurses and nurse practitioners who are implementing this intervention on a daily basis. Finally, we thank Laura Holtz for her contributions to the project and assistance with preparing this manuscript for submission.

Conflict of Interest Disclosures:

\begin{tabular}{|c|c|c|c|c|c|c|c|c|c|c|}
\hline \multirow{2}{*}{$\begin{array}{c}\text { Elements of } \\
\text { Financial/Personal Conflicts }\end{array}$} & \multicolumn{2}{|c|}{ Hickman } & \multicolumn{2}{|c|}{ Unroe } & \multicolumn{2}{|c|}{ Ersek } & \multicolumn{2}{|c|}{ Buente } & \multirow{2}{*}{$\begin{array}{c}\text { Nazir } \\
\text { Yes No }\end{array}$} & Sachs \\
\hline & Yes & No & Yes & No & Yes & No & Yes & No & & Yes No \\
\hline Employment or Affiliation & & & & & & & & & & \\
\hline & & $x$ & & $X$ & & $x$ & & $x$ & $x$ & $x$ \\
\hline Grants/Funds & & $\mathrm{X}$ & & $\mathrm{X}$ & & $\mathrm{X}$ & & $\mathrm{X}$ & $\mathrm{X}$ & $\mathrm{x}$ \\
\hline Honoraria & & $\mathrm{X}$ & & $\mathrm{X}$ & & $\mathrm{x}$ & & $\mathrm{X}$ & $\mathrm{X}$ & $\mathrm{X}$ \\
\hline Speaker Forum & & $\mathrm{X}$ & & $\mathrm{x}$ & & $\mathrm{x}$ & & $\mathrm{X}$ & $\mathrm{X}$ & $\mathrm{x}$ \\
\hline Consultant & & $\mathrm{X}$ & & $\mathrm{X}$ & & $\mathrm{X}$ & & $\mathrm{X}$ & $\mathrm{x}$ & $\mathrm{x}$ \\
\hline Stocks & & $\mathrm{X}$ & & $\mathrm{X}$ & & $\mathrm{X}$ & & $\mathrm{X}$ & $\mathrm{X}$ & $\mathrm{X}$ \\
\hline Royalties & & $\mathrm{X}$ & & $\mathrm{X}$ & & $\mathrm{X}$ & & $\mathrm{X}$ & $\mathrm{x}$ & $\mathrm{x}$ \\
\hline & & & & & & & & & & \\
\hline
\end{tabular}




\begin{tabular}{|c|c|c|c|c|c|c|}
\hline Expert Testimony & $\mathrm{X}$ & $\mathrm{X}$ & $\mathrm{X}$ & $\mathrm{X}$ & $\mathrm{X}$ & $\mathrm{X}$ \\
\hline Board Member & $\bar{x}$ & $\bar{X}$ & $\bar{x}$ & $\bar{x}$ & $\bar{X}$ & $\bar{x}$ \\
\hline Patents & $x$ & $x$ & $\mathrm{x}$ & $\mathrm{X}$ & $\mathrm{x}$ & $\mathrm{x}$ \\
\hline Personal Relationship & $\bar{x}$ & $\mathrm{x}$ & $x$ & $\bar{x}$ & $\bar{X}$ & $\mathrm{X}$ \\
\hline & & & & & & \\
\hline
\end{tabular}

${ }^{*}$ Authors can be listed by abbreviations of their names.

For "yes" x mark(s): give brief explanation below:

Dr. Sachs serves as a consultant to the National Pharmacy and Therapeutics Committee of CVS Caremark and he receives an honorarium for this role.

Author Contributions: Study concept and design: Hickman, Unroe, Ersek, Nazir, Sachs. Acquisition of subjects and/or data: Buente. Analysis and interpretation of data: Hickman, Unroe, Ersek, Buente, Nazir, Sachs. Analysis and interpretation: Hickman, Unroe, Ersek, Buente, Nazir, Sachs. Preparation of manuscript: Hickman, Unroe, Ersek, Buente, Nazir, Sachs.

Sponsor's Role: The project described was supported by Funding Opportunity Number 1E1CMS331082-04-00 from the Centers for Medicare \& Medicaid Services. The contents provided are solely the responsibility of the authors and do not necessarily represent the official views of the United States Department of Health and Human Services or any of its agencies. The investigators retained independence in the conduct of this research. The funding organization did not write or approve this manuscript. 


\section{REFERENCES}

1. Mitchell SL, Teno JM, Miller SC, Mor V. A national study of the location of death for older persons with dementia. J Am Geriatr Soc. 2005;53(2):299-305.

2. Teno JM, Lima JC, Lyons KD. Cancer patient assessment and reports of excellence: reliability and validity of advanced cancer patient perceptions of the quality of care. J Clin Oncol. 2009;27(10):1621-1626.

3. Teno JM, Gozalo P, Mitchell SL, Tyler D, Mor V. Survival after multiple hospitalizations for infections and dehydration in nursing home residents with advanced cognitive impairment. JAMA. 2013;310(3):319-320.

4. Houttekier D, Cohen J, Bilsen J, Addington-Hall J, Onwuteaka-Philipsen BD, Deliens L. Place of death of older persons with dementia. A study in five European countries. J Am Geriatr Soc. 2010;58(4):751-756.

5. Mezey MD DN, Bottrell M, Mitty E, Ramsey G, Farber PostL, et al. Guidelines for end-of-life care in nursing facilities: Principles and recommendations. New York: New York University Division of Nursing, and the Montifiore Medical Center Division of Bioethics. ; 2001.

6. Grabowski DC, Stewart KA, Broderick SM, Coots LA. Predictors of nursing home hospitalization: a review of the literature. Med Care Res Rev. 2008;65(1):3-39.

7. Buchanan JL, Murkofsky RL, O'Malley AJ, et al. Nursing home capabilities and decisions to hospitalize: a survey of medical directors and directors of nursing. J Am Geriatr Soc. 2006;54(3):458-465.

8. Temkin-Greener H, Zheng NT, Xing J, Mukamel DB. Site of death among nursing home residents in the United States: changing patterns, 2003-2007. J Am Med Dir Assoc. 2013;14(10):741-748.

9. Hickman SE, Keevern E, Hammes BJ. Use of the physician orders for life-sustaining treatment program in the clinical setting: a systematic review of the literature. J Am Geriatr Soc. 2015;63(2):341-350.

10. Cantor MD, Pearlman RA. Advance care planning in long-term care facilities. J Am Med Dir Assoc. 2003;4(2):101-108.

11. Silveira MJ, Wiitala W, Piette J. Advance directive completion by elderly Americans: a decade of change. J Am Geriatr Soc. 2014;62(4):706-710.

12. Tolle SW, Tilden VP, Nelson CA, Dunn PM. A prospective study of the efficacy of the physician order form for life-sustaining treatment. J Am Geriatr Soc. 1998;46(9):1097-1102.

13. Hickman SE, Nelson CA, Moss AH, et al. Use of the Physician Orders for Life-Sustaining Treatment (POLST) paradigm program in the hospice setting. J Palliat Med. 2009;12(2):133-141.

14. Hickman SE, Nelson CA, Perrin NA, Moss AH, Hammes BJ, Tolle SW. A comparison of methods to communicate treatment preferences in nursing facilities: traditional practices versus the physician orders for life-sustaining treatment program. J Am Geriatr Soc. 2010;58(7):1241-1248.

15. Hammes BJ, Rooney BL, Gundrum JD, Hickman SE, Hager N. The POLST program: a retrospective review of the demographics of use and outcomes in one community where advance directives are prevalent. J Palliat Med. 2012;15(1):77-85.

16. Fromme EK, Zive D, Schmidt TA, Cook JN, Tolle SW. Association between Physician Orders for Life-Sustaining Treatment for Scope of Treatment and in-hospital death in Oregon. J Am Geriatr Soc. 2014;62(7):1246-1251.

17. Centers for Medicare and Medicaid Services. Initiative to Reduce Avoidable Hospitalization Among Nursing Facility Residents. 2014; http://innovation.cms.gov/initiatives/rahnfr/. Accessed February 7, 2014. 
18. OPTIMISTIC Study . OPTIMISTIC- Optimizing Patient Transfers, Impacting Medical Quality and Improving Symptoms: Transforming Institutional Care. 2013; http://optimistic.medicine.iu.edu/. Accessed December 7, 2015.

19. Unroe KT, Nazir A, Holtz LR, et al. The Optimizing Patient Transfers, Impacting Medical Quality, andImproving Symptoms:Transforming Institutional Care approach: preliminary data from the implementation of a Centers for Medicare and Medicaid Services nursing facility demonstration project. J Am Geriatr Soc. 2015;63(1):165-169.

20. Hickman S, Keevern, E \& Hammes, BJ. A Review of Research on Use of Physician Orders for LifeSustaining Treatment (POLST) in the Clinical Setting. Journal of the American Geriatrics Society. 2015.

21. Flo E BP, Husebo B, et al. Implementing strategies and reseach of advance caer planning in nursing homes: An integrative, systematic review of the literature. BMJ Supp \& Pal Care. 2015;A52.

22. Indianapost.org. The Indiana POST program. 2014; www.indianapost.org. Accessed January 21, 2014.

23. Kelly K, Ersek M, Virani R, Malloy P, Ferrell B. End-of-Life Nursing Education Consortium. Geriatric Training Program: improving palliative care in community geriatric care settings. $J$ Gerontol Nurs. 2008;34(5):28-35.

24. Gundersen Health System. Respecting Choices: Advance Care Planning. 2014.

25. Molloy DW, Guyatt GH, Russo R, et al. Systematic implementation of an advance directive program in nursing homes: a randomized controlled trial. JAMA. 2000;283(11):1437-1444.

26. Kelly A, Conell-Price J, Covinsky K, et al. Length of stay for older adults residing in nursing homes at the end of life. J Am Geriatr Soc. 2010;58(9):1701-1706.

27. Cornally N, McGlade C, Weathers E, et al. Evaluating the systematic implementation of the 'Let Me Decide' advance care planning programme in long term care through focus groups: staff perspectives. BMC palliative care. 2015;14(1):55.

28. You JJ, Downar J, Fowler RA, et al. Barriers to goals of care discussions with seriously ill hospitalized patients and their families: a multicenter survey of clinicians. JAMA internal medicine. 2015;175(4):549-556.

29. Heyland DK, Barwich D, Pichora D, et al. Failure to engage hospitalized elderly patients and their families in advance care planning. JAMA internal medicine. 2013;173(9):778-787.

30. Allison TA, Sudore RL. Disregard of patients' preferences is a medical error: comment on "Failure to engage hospitalized elderly patients and their families in advance care planning". JAMA internal medicine. 2013;173(9):787.

31. Institutes of Medicine. Dying in America: Improving quality and honoring individual preferences near the end of life. Washington, DC2014.

32. Hammes B BL, Silverster W, Wilson K, Schettle S, Maycroft J, Sandoval J, Orders A, Stern M. Implementing a care planning system: Hot to fix the most pervasive errors in health care. In: Blog HA, ed. Vol 20152015.

33. Davies P, Walker AE, Grimshaw JM. A systematic review of the use of theory in the design of guideline dissemination and implementation strategies and interpretation of the results of rigorous evaluations. Implement Sci. 2010;5:14.

34. Madon T, Hofman KJ, Kupfer L, Glass RI. Public health. Implementation science. Science. 2007;318(5857):1728-1729.

35. Jamtvedt G, Young JM, Kristoffersen DT, O'Brien MA, Oxman AD. Does telling people what they have been doing change what they do? A systematic review of the effects of audit and feedback. Qual Saf Health Care. 2006;15(6):433-436. 
36. VanDeusen Lukas C, Engle RL, Holmes SK, et al. Strengthening organizations to implement evidence-based clinical practices. Health Care Manage Rev. 2010;35(3):235-245.

37. Stetler $\mathrm{CB}$, Legro $\mathrm{MW}$, Wallace $\mathrm{CM}$, et al. The role of formative evaluation in implementation research and the QUERI experience. J Gen Intern Med. 2006;21 Suppl 2:S1-8.

38. Jamtvedt G, Young JM, Kristoffersen DT, O'Brien MA, Oxman AD. Audit and feedback: effects on professional practice and health care outcomes. Cochrane Database Syst Rev. 2006(2):CD000259.

39. Van den Block L. Integrating pallative care and advance care planning in nursing homs in Europe: Current state of affairs. BMJ Supp \& Pal Care. 2015;5(Suppl ):A33.

40. Husebo BS, Flo E, Aarsland D, et al. COSMOS--improving the quality of life in nursing home patients: protocol for an effectiveness-implementation cluster randomized clinical hybrid trial. Implement Sci. 2015;10:131.

41. Wysocki A, Thomas KS, Mor V. Functional improvement among short-stay nursing home residents in the MDS 3.0 . J Am Med Dir Assoc. 2015;16(6):470-474.

Supplemental Figure 1: Advance Care Planning Decision Tree. This decision tree is used to assist OPTIMISTIC nurses in identifying the appropriate individual to target for advance care planning and the correct documentation tool to use based on Indiana statutes. 